1 Wakefield AJ, Murch SH, Anthony A, Linnell J, Casson DM, Malik M, et al. Ileal-lymphoid-nodular hyperplasia, non-specific colitis, and pervasive developmental disorder in children. Lancet 1998;351:637-41.

2 Taylor B, Miller E, Farrington CP, Petropoulos M-C, Favot-Mayaud I, Li J, et al. Autism and measles, mump and rubella vaccine: no epidemiological evidence for a causal association. Lancet 1999;353:2026-9.

3 Farrington CP, Miller E, Taylor B. MMR and autism: further evidence against a causal association. Vaccine 2001;19:3632-5.

4 Kaye JA, Melero-Montes M, Jick H. Mumps, measles and rubella vaccine and the incidence of autism recorded by general practitioners: a time trend analysis. BMJ 2001;322:460-3.

5 Dales L, Hammer S, Smith N. Time trends in autism and MMR immunisation in California. JAMA 2001;285:1183-5.

6 DeWilde S, Carey IM, Richards S, Hilton SR, Cook DG. Do children who become autistic consult more often after MMR vaccination? Brit J Gen Pract 2001:51:226-7.

7 Wakefield AJ. Testimony to the Congress of the United States House of Representatives Committee on Government Reform: hearing on the challenges of autism. Why the increased rates? A one year update. Washington. April 2001. www.house.gov/reform/hearings/healthcare/ 01.04.25/wakefield.htm. [accessed 7 February 2002]

8 Kurita H, Kita M, Miyaka A. A comparative study of development and symptoms among disintegrative psychosis and infantile autism with and without speech loss. J Autism Dev Disord 1992;22:175-88.
9 Fombonne E, Chakrabarti S. No evidence for a new variant of measles-mumps-rubella-induced autism. Pediatrics 2001;108:e58.

10 Wakefield A, Anthony A, Murch S, Thomson M, Montgomery SM, Davies S, et al. Enterocolitis and immunodeficiency in children with developmental disorders. Am J Gastroenterol 2000;95:2285-95.

11 Furlano RI, Anthony A, Day R, Brown A, McGarvey L, Thomson MA, et al. Colonic CD8 and $\gamma \mathrm{d}$ T-cell infiltration with epithelial damage in children with autism. J Pediatr 2001;138:366-72.

12 Gershon M. Testimony to the Congress of the United States House of Representatives Committee on Government Reform: hearing on the challenges of autism. Why the increased rates? A one year update. Washington. April 2001. www.house.gov/reform/hearings/healthcare/ 01.04.25/gershon.htm. [accessed 8 February 2002]

13 Halsey NA, Hyman SL. Conference writing panel. Measles-mumpsrubella vaccine and autistic spectrum disorder: report from the new challenges in childhood immunizations conference convened in Oak Brook, Illinois, Jun 12-13, 2000. Pediatrics 2001;107(5):1-23. www.pediatrics.org/ cgi/content/full/107/5/e84

14 Lord C, Rutter M, Le Couteur A. Autism diagnostic interview-revised: a revised version of a diagnostic interview for caregivers of individuals with possible pervasive developmental disorders. J Autism Dev Disord 1994;24:659-85.

(Accepted 24 January 2002)

\title{
Socioeconomic differences in Swedish children and adolescents injured in road traffic incidents: cross sectional study
}

\author{
Lucie Laflamme, Karin Engström
}

Karolinska

Institutet,

Department of

Public Health

Sciences, Division of

Social Medicine,

SE-171 76

Stockholm, Sweden

Lucie Laflamme

associate professor

Karin Engström

research fellow

Correspondence to:

L Laflamme

lucie.laflamme@

phs.ki.se

BMJ 2002;324:396-7
Traffic related injuries are among the most common causes of death in childhood and in youth. ${ }^{1}$ Young people belonging to a low social class and living in deprived socioeconomic areas are consistently at greater risk than others. ${ }^{2}{ }^{3}$ The extent to which socioeconomic differences in risks from traffic injury vary during childhood and adolescence deserves consideration. ${ }^{45}$ We examined socioeconomic patterning in Swedish children and adolescents injured in road traffic incidents, considering four categories of road users.

\section{Methods and results}

We created a dataset of about 2.2 million children and adolescents (aged 0-19 years) living in Sweden at some time during 1990-4 by linking records from 13 Swedish national registers. We established their sex and year of birth by linking the Swedish population register to the national censuses of 1985 or 1990 or to the medical register of births, according to the person's age.

Subjects were divided into four age groups and allocated to one of four household socioeconomic statuses (table) based on that of the parent with the highest status. The Swedish socioeconomic status is a measure of class, based on occupation and the average level of education required for any particular occupation. Status was attributed to the parents by Statistics Sweden in the Swedish population and housing census of 1990.

We linked the data on sex, year of birth, and socioeconomic status of the young people to five annual national hospital discharge registers (1990-4) and to the national causes of death register. The latter has about $4.5 \%$ of cases lacking information on either E-code (cause of injury) or personal identification number of the injured person. We considered fatal and non-fatal injuries, based on the assumption that the number of lethal injuries did not vary greatly between socioeconomic groups. ${ }^{2}$ We avoided double counting by excluding from the outpatient register any person with the same diagnosis in both registers within two months.

Four diagnostic categories were considered according to ICD-9 (international classification of diseases, ninth revision): pedestrian injuries, bicycle related injuries, injuries as motor vehicle passenger, and injuries as motor vehicle driver (table) (13 772 road traffic injuries in total).

We performed a series of regressions by category of injury diagnosis for each age group to calculate the relative risk of injury according to socioeconomic status. Children of households classified as high or intermediate level salaried employees were used as the reference group. We tested for-but did not find-a possible modification effect of sex of child on socioeconomic patterning; therefore boys and girls were considered together. However, the model used for the later regressions did include the variable for sex of child to test whether boys were at a much greater risk than girls, regardless of socioeconomic status. All analyses were performed using SAS version 6.12.

The relative risks of being injured in a traffic related incident were generally-but not consistently-greater for boys than for girls (table). Socioeconomic differences are negligible in the early years of life (0-4 years) but for all other age groups the relative risks are appreciably higher for children of unskilled workers than for those of high or intermediate level salaried employees. Relative risks are particularly pronounced at 10-14 years of age for non-pedestrians, and at 15-19 years for drivers and riders of motorised vehicles. 
Relative risks (95\% confidence intervals) of being injured in a road traffic incident*

\begin{tabular}{|c|c|c|c|c|}
\hline \multirow[b]{2}{*}{ Variables } & \multirow[b]{2}{*}{ Pedestrian } & \multirow[b]{2}{*}{ Bicyclist } & \multicolumn{2}{|c|}{ Motor vehicle } \\
\hline & & & Passenger & Drivert \\
\hline ICD-9 codes & $\mathrm{E} 819 \mathrm{H}$ & E807, E819G, E826 & E819B, E819D & E819A, E819C, E819J \\
\hline \multicolumn{5}{|l|}{ Age $0-4$ years } \\
\hline Injuries per 100000 person years & 5.61 & 18.02 & 8.05 & \\
\hline \multicolumn{5}{|l|}{ Sex: } \\
\hline Female & 1.0 & 1.0 & 1.0 & \\
\hline Male & $1.40(1.03$ to 1.90$)$ & 1.44 (1.21 to 1.72$)$ & 0.94 (0.74 to 1.20$)$ & \\
\hline \multicolumn{5}{|l|}{ Household socioeconomic status: } \\
\hline Employees with high or intermediate salaries & 1.0 & 1.0 & 1.0 & \\
\hline Employees with low salaries & $0.83(0.46$ to 1.48$)$ & 1.06 (0.79 to 1.41$)$ & 0.88 (0.56 to 1.38$)$ & \\
\hline Skilled workers & 1.12 (0.71 to 1.78$)$ & 1.10 (0.86 to 1.41$)$ & 0.95 (0.65 to 1.40$)$ & \\
\hline Unskilled workers & 1.55 (1.01 to 2.39 ) & $1.10(0.85$ to 1.42$)$ & $1.23(0.85$ to 1.77$)$ & \\
\hline \multicolumn{5}{|l|}{ Age 5-9 years } \\
\hline Injuries per 100000 person years & 12.78 & 9.88 & 14.11 & \\
\hline \multicolumn{5}{|l|}{ Sex: } \\
\hline Female & 1.0 & 1.0 & 1.0 & \\
\hline Male & 1.62 (1.30 to 2.02$)$ & 1.55 (1.43 to 1.68$)$ & $1.16(0.94$ to 1.42$)$ & \\
\hline \multicolumn{5}{|l|}{ Household socioeconomic status: } \\
\hline Employees with high or intermediate salaries & 1.0 & 1.0 & 1.0 & \\
\hline Employees with low salaries & $1.11(0.75$ to 1.66$)$ & 1.27 (1.11 to 1.44$)$ & 1.18 (0.84 to 1.66$)$ & \\
\hline Skilled workers & 1.38 (0.99 to 1.98$)$ & 1.47 (1.31 to 1.64$)$ & 1.17 (0.86 to 1.59$)$ & \\
\hline Unskilled workers & 2.33 (1.74 to 3.12 ) & $1.51(1.35$ to 1.75$)$ & 1.40 (1.04 to 1.88$)$ & \\
\hline \multicolumn{5}{|l|}{ Age 10-14 years } \\
\hline Injuries per 100000 person years & 16.53 & 130.44 & 17.22 & 25.78 \\
\hline \multicolumn{5}{|l|}{ Sex: } \\
\hline Female & 1.0 & 1.0 & 1.0 & 1.0 \\
\hline Male & 1.04 (0.86 to 1.27$)$ & 1.98 (1.83 to 2.13$)$ & 1.01 (0.85 to 1.22$)$ & 5.72 (4.62 to 7.08$)$ \\
\hline \multicolumn{5}{|l|}{ Household socioeconomic status: } \\
\hline Employees with high or intermediate salaries & 1.0 & 1.0 & 1.0 & 1.0 \\
\hline Employees with low salaries & 1.21 (0.90 to 1.62$)$ & 1.14 (1.02 to 1.27$)$ & 1.37 (1.03 to 1.83$)$ & $1.76(1.36$ to 2.27$)$ \\
\hline Skilled workers & 0.84 (0.61 to 1.16$)$ & 1.18 (1.07 to 1.32$)$ & 1.06 (0.78 to 1.44$)$ & $2.32(1.85$ to 2.90$)$ \\
\hline Unskilled workers & 1.09 (0.81 to 1.46$)$ & 1.37 (1.24 to 1.51$)$ & $1.36(1.03$ to 1.80$)$ & 2.18 (1.73 to 2.74$)$ \\
\hline \multicolumn{5}{|l|}{ Age 15-19 years } \\
\hline Injuries per 100000 person years & 17.34 & 69.96 & 58.41 & 169.13 \\
\hline \multicolumn{5}{|l|}{ Sex: } \\
\hline Female & 1.0 & 1.0 & 1.0 & 1.0 \\
\hline Male & 1.06 (0.88 to 1.28$)$ & $1.38(1.25$ to 1.51$)$ & 0.99 (0.89 to 1.09$)$ & 5.38 (4.96 to 5.83$)$ \\
\hline \multicolumn{5}{|l|}{ Household socioeconomic status: } \\
\hline Employees with high or intermediate salaries & 1.0 & 1.0 & 1.0 & 1.0 \\
\hline Employees with low salaries & 1.05 (0.78 to 1.41$)$ & $0.99(0.85$ to 1.14$)$ & 1.34 (1.14 to 1.58$)$ & $1.41(1.29$ to 1.55$)$ \\
\hline Skilled workers & 0.97 (0.72 to 1.31$)$ & $1.06(0.92$ to 1.22$)$ & 1.64 (1.41 to 1.90$)$ & $1.74(1.60$ to 1.90$)$ \\
\hline Unskilled workers & 1.55 (1.20 to 2.00$)$ & $1.22(1.07$ to 1.40$)$ & 1.96 (1.70 to 2.26$)$ & $1.70(1.57$ to 1.86$)$ \\
\hline
\end{tabular}

*Diagnostic category is according to ICD-9 (international classification of diseases, ninth revision).

fFor moped related injuries, both drivers and passengers fall into the category "driver" because the classification does not distinguish between those two groups.

\section{Comment}

The relative risks of being injured in a road traffic incident are higher for 5-19 year olds belonging to a low social class than for those belonging to other classes. Specifically, socioeconomic differences are small for 0-14 year olds who are injured while they are passengers of motor vehicles. The socioeconomic gradient in 5-19 year olds with bicycle related injuries and 15-19 year olds injured as motor vehicle passengers and drivers, however, deserve attention.

Contributors: LL had the original idea for the study, participated in the study design, and wrote the paper. KE participated in the study design, built the dataset, and took part in the discussion of the results. LL is the guarantor.

Funding: Swedish Transport and Communications Research Board and Swedish Council for Social Research. Competing interests: None declared.

1 World Health Organization. Injury. A leading cause of the global burden of disease. Geneva: WHO, 1999.
2 Laflamme, L. Social inequality in injury risks. Accumulated knowledge and strategies for the future. Stockholm: National Institute of Public Health, 1998:33.

3 Laflamme L, Diderichsen F. Social differences in traffic injuries in childhood and youth. A review and a frame of reference for the unanswered questions. Inj Prev 2000;6:293-8.

4 West P. Health inequalities in the early years: is there equalisation in youth? Soc Sci Med 1997;44:833-58.

5 Hasselberg M, Laflamme L, Ringbäck Weitoft G. Socio-economic differences in road-traffic injuries during childhood and youth-a closer look at different kinds of road users. J Epidemiol Community Health 2001;55:858-62.

(Accepted 10 July 2001)

\section{Correction}

Post-combat syndromes from the Boer war to the Gulf war: a cluster analysis of their nature and attribution

In this article in our "War 2002" theme issue (9 February, pp 321-4) the authors, Edgar Jones and colleagues, inadvertently used the word psychoneurosis instead of neuropsychiatric in their discussion. The second sentence of the section "Implications for Gulf war syndrome" should read "Although most cases fell into the neuropsychiatric cluster, Gulf war veterans are found in all three groups." 